\title{
Ensino de Ciências ao Aluno Surdo: Um Estudo de Caso sobre a Sala Regular, o Atendimento Educacional Especializado e o Intérprete Educacional
}

\author{
Teaching Science to deaf Students: A Case Study on Regular Classrooms, \\ the Specialized Educational Service and Educational Interpreters
}

Juliani Flávia de Oliveira, Denise Pereira de Alcantara Ferraz

\begin{abstract}
Palavras-chave Resumo As escolas regulares devem assegurar aos alunos surdos uma
\end{abstract} Ensino de Ciências; Educação Especial dentro da perspectiva inclusiva mediante o acesso Atendimento ao Atendimento Educacional Especializado (AEE), bem como uma Educacional educação bilíngue na presença do Intérprete Educacional (IE). Diante Especializado; destas preconizações legais, esta pesquisa baseou-se em um estudo de Intérprete de Libras; caso, de abordagem qualitativa, cujo intuito foi analisar o processo de Surdez. inclusão escolar e o ensino de Ciências oferecido à uma aluna surda do oitavo ano do Ensino Fundamental de uma instituição da rede pública situada ao sul de Minas Gerais. A pesquisa buscou responder as seguintes questões norteadoras: quais estratégias são utilizadas pelo professor de Ciências, AEE e IE para ensinar/interpretar Ciências? Quais são as suas dificuldades? Estes setores se articulam? Como o ensino bilíngue tem sido proporcionado? Para atender a tais questões, foram realizadas entrevistas semiestruturadas com os referidos profissionais e com um membro familiar da aluna. Os dados obtidos foram analisados com base na Análise de Conteúdo. Os resultados demonstraram que os profissionais recorrem à recursos visuais $\mathrm{e}$ materiais concretos como facilitadores para o ensino de Ciências. Contudo, o desconhecimento da Libras dificulta a comunicação entre professor/aluno, direcionando uma sobrecarga de funções ao intérprete. A articulação entre os setores é quase inexistente entre o professor e o intérprete, o que acarreta dificuldades diante da interpretação de conteúdos científicos. Enfatiza-se, portanto, a necessidade de maiores reflexões quanto à ampliação lexical em Libras correspondente a termos científicos, assim como a ampliação de discussões acerca da formação desses profissionais e seus diálogos nos contextos escolares.

Submetido em 26 de junho de 2020 Aceito para publicação em 14 de dezembro de 2020 Publicado em 16 de março de 2021 
Keywords Abstract Regular schools must ensure that students who are deaf Science teaching; have a special education from an inclusive perspective, thorough

Specialized access to a Specialized Educational Service (SES) and a bilingual Educational Service; education in the presence of the educational interpreter (EI). Given

Brazilian these legal recommendations, this qualitative case study examined sign language the process of inclusion and teaching of science of a deaf student interpreter; from the eighth grade in a public elementary school in the south of

Deafness. Minas Gerais. The research sought to answer the following guiding questions: What strategies are used by the science teacher, the SES and the EI to teach/interpret science? What are their difficulties? Do these sectors articulate with each other? How has bilingual education been provided? To answer such questions, semi-structured interviews were conducted with these professionals and with a family member of the student. Content Analysis was conducted on the data obtained. The results showed that the professionals use solid visual and material resources as facilitators for science teaching. However, the lack of knowledge about Brazilian sign language makes the communication between teacher and student difficult, leaving the interpreter with an overload of functions. The articulation is almost non-existent between the teacher and the interpreter, which causes difficulties when interpreting scientific content. The study highlights the importance of further reflection on lexical expansion in Brazilian sign language regarding scientific terms, as well as broader discussions about the training of these professionals and their communication in school contexts.

\section{A inclusão do aluno surdo na escola regular: o cenário político brasileiro}

A perspectiva educacional inclusiva iniciou-se a partir das discussões promovidas na Conferência Mundial sobre Necessidades Educativas Especiais: Acesso e Qualidade, realizada na Espanha, em 1994. Este evento originou o documento intitulado "Declaração de Salamanca" o qual discorria sobre os princípios acerca da Educação Especial, destacando o fato de a escola regular ser a principal responsável por atender as diferentes necessidades dos alunos, buscando alternativas que facilitem seus processos de aprendizagem (MEC, 1994). É válido ressaltar que a perspectiva de inclusão escolar, compreendida nesse documento, visa a incluir não apenas os alunos com deficiência no espaço escolar, mas toda a heterogeneidade de estudantes que compõe o meio social, independente de questões socioeconômicas, étnicas, geográficas, de gênero, etc.

As especificações legais para a inserção da perspectiva inclusiva nas escolas do Brasil iniciaram-se em 1996, com a publicação da Lei de Diretrizes e Bases da Educação Nacional 
(LDB). Esta esclareceu que, ao Público-Alvo da Educação Especial (PAEE), caracterizado por alunos com deficiências (físicas, sensoriais ou intelectuais), com transtornos globais do desenvolvimento e com altas habilidades/superdotação, é garantida a matrícula em classes comuns do ensino regular, bem como uma reestruturação do ambiente escolar para a sua permanência e seu sucesso educativo (Lei n. 9394, 1996).

No grupo dos alunos PAEE, encontram-se os indivíduos da comunidade surda, a qual tem como língua oficial no país a Língua Brasileira de Sinais - Libras, reconhecida legalmente em 2002 (Lei n. 10436, 2002). Esta característica, dentro da perspectiva de escola inclusiva, permite aos alunos surdos do Brasil a disponibilização de uma educação bilíngue, mediante a presença de Tradutores e de Intérpretes de Libras Língua Portuguesa.

A educação bilíngue consiste em ensinar aos alunos surdos duas línguas: a Língua de Sinais - que será sua primeira língua (L1) - e a modalidade escrita da língua utilizada pela comunidade ouvinte de seu país - segunda língua (L2). Esta perspectiva, uma conquista para a comunidade surda no campo educacional, defende que a pessoa surda não necessita de mudanças, como a aprendizagem da fala, para se enquadrar aos espaços onde encontram-se pessoas ouvintes. Ela deve assumir a sua identidade, vivêla e aceitá-la, reconhecendo-se como membro de uma comunidade com cultura e com forma de comunicação própria (Lorenzini, 2004). Assim, considerando e valorizando as especificidades linguísticas dos alunos surdos no âmbito escolar, o Intérprete Educacional (IE) tem como função intermediar as relações entre os alunos surdos e os professores, assim como as relações entre os alunos surdos e seus colegas ouvintes (Quadros, 2004).

Além do serviço mencionado, o aluno surdo também dispõe do Atendimento Educacional Especializado (AEE). Segundo a Resolução n. 4 de 2009, de 2 de outubro de 2009, (Resolução n. 4, 2009) esse direito deve ser oferecido à todos os alunos que compõem o PAEE, durante o contra turno das aulas regulares e por um professor especializado em Educação Especial. Para tanto, o professor do AEE responsabilizase por elaborar, em articulação com a comunidade escolar, um plano de atendimento para cada aluno PAEE presente na escola, de modo a complementar ou suplementar o ensino fornecido nas classes regulares, utilizando-se de métodos e recursos específicos para o tipo de necessidade especial do aluno e com vista a eliminar as barreiras para o desenvolvimento de sua aprendizagem (Resolução n. 4,2009). Além disso, essa assistência deve ser oferecida em Salas de Recursos Multifuncionais (SRM), que correspondem a espaços dotados de recursos e materiais para o auxílio da aprendizagem do PAEE, tais como lupas, microcomputadores, recursos de tecnologia assistiva, etc.

Especificamente ao AEE para os alunos surdos, a Política Nacional de Educação Especial na Perspectiva da Educação Inclusiva (PNEE-EI) apresenta que este serviço deve ser realizado "[...] mediante a atuação de profissionais com conhecimentos específicos no ensino da Língua Brasileira de Sinais, da Língua Portuguesa na modalidade escrita como segunda língua" (MEC, 2008, p. 17).

Um terceiro profissional que estabelece uma relação direta com o aluno surdo 
nas escolas regulares é o professor de Ciências, atuante no Ensino Fundamental. Este é responsável por ensinar à todos os alunos, conteúdos científicos acerca dos fenômenos químicos, físicos e biológicos.

No que tange ao perfil do professor da sala regular para atender à diversidade do PAEE, a LDB de 1996 propõe, em seu artigo 59º que os sistemas de ensino deverão assegurar: "professores do ensino regular capacitados para a integração desses educandos nas classes comuns" (Lei n. 9394, 1996). A descrição dos atributos deste professor "capacitado" encontra-se na Resolução n. 2, de 11 de setembro de 2001, a qual institui as Diretrizes Nacionais para a Educação Especial na Educação Básica (Resolução n. 2, 2001). Em seu artigo $18^{\circ}$, esta resolução estabelece que,

$\$ 1^{\circ}$ São considerados professores capacitados para atuar em classes comuns com alunos que apresentam necessidades educacionais especiais aqueles que comprovem que, em sua formação, de nível médio ou superior, foram incluídos conteúdos sobre educação especial adequados ao desenvolvimento de competências e valores para:

I - perceber as necessidades educacionais especiais dos alunos e valorizar a educação inclusiva;

II - flexibilizar a ação pedagógica nas diferentes áreas de conhecimento de modo adequado às necessidades especiais de aprendizagem;

III - avaliar continuamente a eficácia do processo educativo para o atendimento de necessidades educacionais especiais;

IV - atuar em equipe, inclusive com professores especializados em educação especial. (Resolução n. 2, 2001, p. 5).

A partir da explanação de algumas das políticas orientadoras da atuação dos profissionais que estabelecem uma relação direta com o aluno surdo nas escolas regulares, o item a seguir apresenta considerações sobre as pesquisas referentes ao ensino de Ciências para alunos surdos.

\section{Ensino de Ciências ao aluno surdo: as investigações na área}

O número de pesquisas referentes ao ensino de Ciências aos alunos surdos tem crescido ao longo dos anos, haja vista as investigações que se propuseram analisar o conjunto de publicações acerca desta temática (Santana \& Sofiato, 2018; Santos \& Lopes, 2017).

Santana e Sofiato (2018), em uma pesquisa que objetivou evidenciar o estado da arte das investigações sobre o ensino de Ciências aos estudantes surdos, produzidas entre os anos de 2012 a 2017, em bancos de dissertações e teses de universidades brasileiras, bem como em revistas nacionais e internacionais, localizaram 101 trabalhos. 
Nesta perspectiva, esses trabalhos foram distribuídos em sete categorias de acordo com o objetivo das pesquisas. Entre as categorias, ressalta-se aquela na qual se encontravam trabalhos que visaram investigar as interações e narrativas em aulas de Ciências, entre alunos, professores e intérpretes. Do total de trabalhos mapeados, apenas 7,92\% foram inseridos nesta categoria. Estes achados evidenciam o caráter incipiente das pesquisas nesta perspectiva, bem como evidenciam a carência de pesquisas que tratam da articulação entre o ensino de Ciências e o professor especialista atuante no AEE aspecto não identificado no trabalho supracitado.

Diante disso, os autores ressaltam a importância de pesquisas que busquem investigar as dificuldades e os desafios do processo de escolarização dos alunos surdos no ensino de Ciências, visando identificar formas de superar os obstáculos mediante diferentes possibilidades de trabalhos entre professores e intérpretes (Santana \& Sofiato, 2018).

Destaca-se, nesta continuidade, os trabalhos de Oliveira e Benite (2015a; 2015b) e Oliveira et al. (2012) os quais, analisando cenários de escola regular na presença de estudantes surdos, manifestam, em seus resultados, aspectos como: a dificuldade de efetivação do ensino bilíngue nas escolas, haja vista o caráter secundário que assume na organização escolar; a alfabetização tardia dos alunos surdos que, por desconhecer a Libras e a Língua Portuguesa, a apropriação da linguagem científica torna-se obstaculizada; as potencialidades da didática multissensorial; a falta de conhecimento dos intérpretes referente aos conhecimentos científicos e o consequente comprometimento da interpretação; a importância do trabalho colaborativo entre os diversos âmbitos escolares; a necessidade do conhecimento mínimo de Libras pelos professores de modo a proporcionar a comunicação com o aluno surdo e o planejamento adequado das atividades.

Além disso, segundo o levantamento e análise realizado por Crittelli Amado (2017), grande parte das pesquisas sobre o ensino de Ciências aos alunos surdos fazem o uso do referencial teórico da abordagem sócio-histórica de Vigotsky para compreender o processo de aprendizagem dos alunos surdos no que diz respeito aos conteúdos científicos.

No que tange à inclusão escolar dos alunos com deficiência, a abordagem sóciohistórica de Vigotsky (1997) se constitui como um dos principais referenciais teóricos que legitimam a inserção desses alunos nos espaços escolares, principalmente pela ênfase que é dada a importância das interações sociais e das interações com objetos no processo do desenvolvimento cognitivo.

Segundo Galvão Filho (2012), no que diz respeito as pessoas com deficiência, as suas relações sociais, bem como as suas interações com objetos, encontram limitações advindas da própria deficiência, pelo fato de não ver, não ouvir, não poder movimentarse, etc. Entretanto, na concepção de Vigotsky (1997), as crianças com deficiência não estarão fadadas ao não desenvolvimento, pois as suas limitações advindas da deficiência funcionarão como uma força propulsora para o encontro de "rotas alternativas" de 
compensação para o seu desenvolvimento. Galvão Filho (2012) apresenta que esse processo de compensação pode ser estimulado mediante o fornecimento de instrumentos mediadores que, de certa forma, neutralizam as barreiras, tais como os recursos de tecnologias assistivas, o fornecimento de ambientes que proporcionem a interação com o conteúdo e com os outros alunos, bem como com os professores, com as famílias e com as comunidades.

Diante disso, ressalta-se a importância da promoção de ambientes de aprendizagem que forneçam os subsídios para as "rotas alternativas" aos alunos, visto que a metodologia de ensino tradicional, livresco e expositivo, na qual o aluno assume a posição de um agente passivo de sua aprendizagem, certamente não abarcará a heterogeneidade de alunos presentes em sala de aula.

A partir destas considerações, o objetivo geral desta pesquisa foi analisar o processo de inclusão escolar e o ensino de Ciências oferecido à uma aluna surda do oitavo ano do Ensino Fundamental de uma instituição da rede pública situada ao sul de Minas Gerais. Diante disso, foram elencados os seguintes objetivos específicos: i) caracterizar as estratégias de ensino e os desafios vivenciados pelos profissionais da educação, sendo eles: o professor de Ciências, o professor do AEE e o IE diante da inclusão e do ensino de Ciências ao aluno surdo; e ii) identificar e analisar as possibilidades de articulação entre o AEE, IE e professor de Ciências.

No item a seguir, são identificados os caminhos metodológicos percorridos no presente estudo.

\section{Percurso metodológico da pesquisa}

Esta pesquisa foi realizada utilizando a abordagem de pesquisa qualitativa, a qual, para Yin (2016), permite, entre outras características, estudar o significado da vida das pessoas em sua realidade, representando as suas opiniões e as suas perspectivas. Além disso, esta abordagem permite que os dados sejam apresentados por múltiplas fontes de evidência, baseando-se na triangulação destes (Yin, 2001; 2016).

O estudo de caso, de acordo com Yin (2001), é um método que permite o estudo aprofundado de um ou poucos objetos, possibilitando o seu conhecimento amplo e detalhado. No caso do presente estudo, a principal unidade de análise correspondeu a uma aluna surda, bem como os serviços proporcionados na educação regular com vistas a sua inclusão, principalmente no que tange ao ensino de Ciências. No momento da investigação, a discente frequentava o oitavo ano do Ensino Fundamental e possuía 16 anos. Aos dois anos de idade, a aluna foi diagnosticada com surdez bilateral profunda e congênita e, aos sete anos, realizou um implante coclear. Esta unidade de análise foi definida em razão da aluna apresentar um alto desempenho escolar, tanto na disciplina de Ciências, quanto nas demais.

No período da pesquisa, a rotina escolar da aluna era composta da seguinte forma: em um dia especificado da semana, no período matutino, a aluna frequentava o AEE com duração de 50 minutos. Além disso, durante o período vespertino, de segunda-feira 
a sexta-feira, ela frequentava as cinco aulas nas classes regulares com os seus colegas ouvintes, totalizando aproximadamente cinco horas por dia. As aulas eram lecionadas por diferentes professores regulares de acordo com as diferentes disciplinas, todas na presença do mesmo intérprete educacional.

Como esta pesquisa visa contribuir com reflexões e possibilidades perante a promoção do ensino de Ciências de forma inclusiva aos alunos surdos nas escolas regulares, esta investigação explana e discute apenas as informações referentes ao contexto de escolarização regular vivenciado pela aluna, não abarcando, desta forma, as suas vivências em serviços e espaços para além da escola regular, como as suas experiências em escolas especiais.

A instituição escolar investigada corresponde a uma escola de Ensino Fundamental e Médio da rede estadual e pública de ensino. Esta encontra-se situada em uma cidade de pequeno porte - com aproximadamente três mil habitantes - localizada ao sul de Minas Gerais.

A partir do objetivo elencado para o estudo, foram definidos os seguintes participantes para a pesquisa: a professora de Ciências, a professora do AEE e o intérprete educacional. Visando conhecer o percurso escolar da aluna e os aspectos de seu diagnóstico, considerou-se importante a participação de um membro familiar da aluna. Assim sendo, a mãe da discente também participou do estudo. As características dos participantes encontram-se dispostas na Figura 1.

Figura 1. Caracterização dos participantes

\begin{tabular}{|l|l|l|l|l|}
\hline Participantes & $\begin{array}{l}\text { Sigla de } \\
\text { identificação }\end{array}$ & Formação & $\begin{array}{l}\text { Fluência em } \\
\text { Libras }\end{array}$ & $\begin{array}{l}\text { Tempo de } \\
\text { trabalho com a } \\
\text { aluna }\end{array}$ \\
\hline $\begin{array}{l}\text { Professora de } \\
\text { Ciências }\end{array}$ & PC & $\begin{array}{l}\text { Licenciatura em Ciências } \\
\text { Biológicas, } \\
\text { Pós-graduação em Educação } \\
\text { Especial e Inclusiva }\end{array}$ & Não & 2 anos \\
\hline $\begin{array}{l}\text { Professora do } \\
\text { AEE }\end{array}$ & PSR & $\begin{array}{l}\text { Pedagogia, } \\
\text { Pós-graduação em deficiência } \\
\text { intelectual e múltipla }\end{array}$ & Não & 3 anos \\
\hline $\begin{array}{l}\text { Intérprete } \\
\text { Educacional }\end{array}$ & IEA & $\begin{array}{l}\text { Licenciatura em Educação Física, } \\
\text { Pós-graduação em Libras }\end{array}$ & Sim & 3 anos \\
\hline Mãe da aluna & M1 & Pedagogia & Não & Não se aplica \\
\hline
\end{tabular}

Fonte: Dados de pesquisa.

Os instrumentos para a coleta de dados, utilizados neste estudo, foram entrevistas semiestruturadas ou qualitativas com os participantes especificados. Yin (2016) aponta que, neste tipo de entrevista, a relação entre o pesquisador e o participante não ocorre 
por meio de um roteiro rígido, pois as perguntas geralmente são abertas, permitindo o modo de conversa. Além disso, o Plano de Desenvolvimento Individual (PDI) ${ }^{1}$, elaborado pela professora do AEE, também constituiu os dados.

No que tange ao procedimento de construção dos dados, foi realizado um contato prévio com um responsável pela aluna surda para a explicação dos objetivos e para a autorização do estudo. Também foi realizado um contato prévio com a direção da escolaalvo para o consentimento da pesquisa. No contato inicial com os participantes, foram estabelecidas as datas para a coleta dos dados e foram entregues as cartas de apresentação, os Termos de Consentimento Livre e Esclarecido e os roteiros de entrevistas.

Todos os participantes consentiram a participação no estudo e, diante disso, as entrevistas foram realizadas pela primeira autora deste trabalho. No caso dos profissionais escolares, estas ocorreram nas próprias dependências da escola. A entrevista com a mãe da aluna sucedeu em sua residência. Estas entrevistas foram gravadas conforme a permissão dos participantes. Após esse processo, os materiais disponíveis foram fotografados e as entrevistas gravadas foram transcritas.

As entrevistas transcritas, os documentos PDI e as fotografias constituíram o conjunto de dados desta pesquisa. Para a análise dos dados, as autoras deste estudo utilizaram o método de Análise de Conteúdo proposto por Bardin (2011).

De modo a acompanhar o processo desenvolvido segundo as fases elencadas por Bardin (2011), apresenta-se que, durante fase inicial da análise, os dados coletados foram organizados de modo a constituir o corpus de análise da pesquisa. Esta fase compreendeu a leitura flutuante com o intuito de reconhecer aspectos dos materiais que se aproximavam dos objetivos elaborados para o estudo. As unidades de registro, ou seja, as menções que compreendiam o interesse da pesquisa foram codificadas formando agregados. Feito esse processo, os dados foram organizados em categorias que expressassem elementos comuns.

Sendo assim, as categorias que emergiram dos dados compreenderam: i) Estratégias de ensino/interpretação utilizadas pelos profissionais; ii) Dificuldades e desafios; e iii) Pontos de articulação entre os setores. Na fase final, de inferência e interpretação dos dados segundo Bardin (2011), buscou-se analisar os dados tendo em vista o referencial teórico do estudo, o qual foi composto pelas políticas públicas de educação especial na perspectiva inclusiva, os estudos acerca da inclusão dos alunos nas escolas regulares e pesquisas referentes ao ensino de Ciências. Os resultados e as discussões provenientes do processo de análise estão dispostos no item a seguir.

\footnotetext{
1 Na escola analisada, o Plano de Desenvolvimento Individual (PDI) consiste em um plano de AEE, elaborado pela professora do AEE em articulação com professores do ensino regular e com a família do aluno. Todo aluno PAEE dispõe de um documento PDI no qual encontram-se as suas informações pessoais, bem como dados referentes ao seu percurso escolar.
} 


\section{Resultados e discussões}

\section{Estratégias utilizadas para a inclusão e para o ensino de Ciências à aluna surda}

De acordo com Lacerda (2014), com frequência, as estratégias escolhidas pelos professores das diferentes disciplinas são pensadas a partir de sua visão, sua língua e suas vivências anteriores, geralmente com alunos ouvintes. Todavia, ao matricular-se um aluno surdo na escola, é necessário que o professor repense e reorganize as suas formas de ensinar, de modo que o estudante - com peculiaridades linguísticas e com conceitos construídos principalmente mediante as suas experiências visuais - tenha sua aprendizagem acessível e favorecida.

Diante disso, observou-se que a PC, ao vivenciar a experiência de ensinar a aluna surda, incluiu em seu planejamento de aulas a exploração de recursos visuais e materiais concretos para a explanação dos conteúdos científicos. Esta menciona que recorre à vídeos, imagens e banners (Figura 2), bem como salienta que solicita aos alunos trabalhos escolares que envolvem a montagem de maquetes (Figura 3) e de jogos. No tocante às aulas laboratoriais, estas não são realizadas devido à falta de um laboratório de Ciências na escola.

Figura 2. Materiais didáticos utilizados para o ensino de Ciências

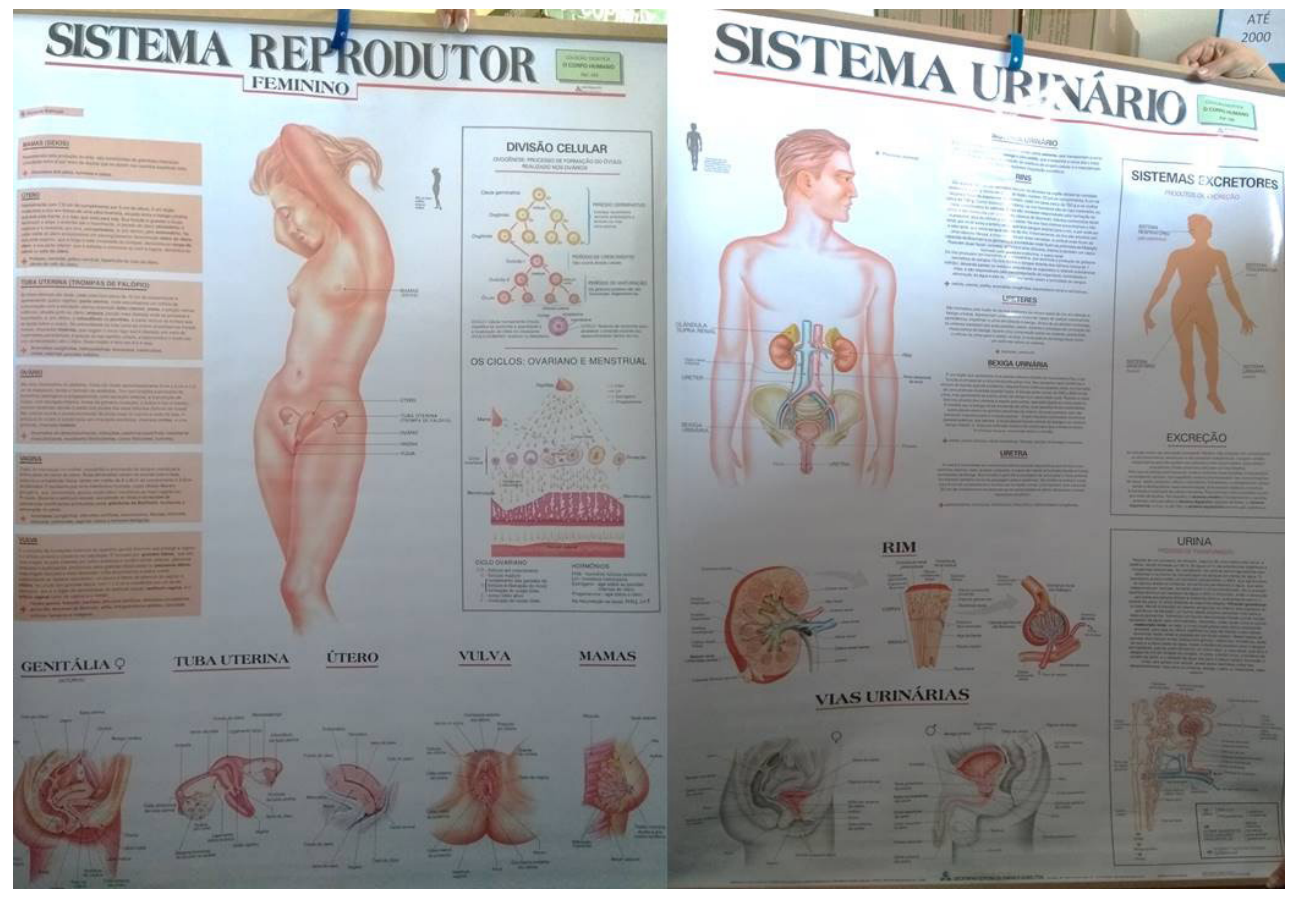

Fonte: Dados de pesquisa. 
Figura 3. Maquetes sobre estruturas celulares confeccionadas pelos alunos

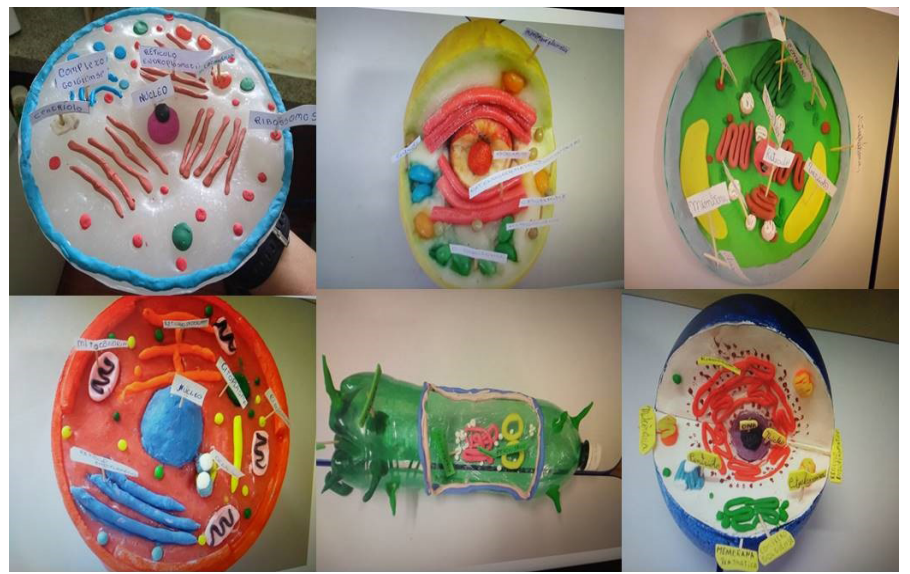

Fonte: Dados de pesquisa.

Nessa continuidade, a professora ainda relata: "[...] procuro colocar mais recursos visuais pra ela entender melhor, não só ela, isso aí ajuda a turma." (PC), evidenciando que, assim como os alunos surdos apreendem os conhecimentos principalmente a partir do canal visual, os alunos ouvintes também podem ser beneficiados com a exploração desses recursos, visto que os conhecimentos científicos envolvem discussões acerca de elementos que nem sempre podem ser visualizados sem a utilização de instrumentos no cotidiano, tais como as células, os protozoários, as bactérias, os fungos etc. Em pesquisa similar realizada por Oliveira, Ferraz e Ribeiro (2019) também "foi possível evidenciar que todas as professoras entrevistadas procuram utilizar metodologias que vão além da exposição do conteúdo através de aulas teóricas e que todas elas apontam a necessidade de trabalhar o concreto com os alunos que compreendem o PAEE” (p. 64).

Entretanto, vale lembrar que, para além da utilização dos recursos visuais e materiais didáticos com o intuito de ilustrar os conceitos, outras formas de ensinar - não mencionadas pela PC e abordadas nas investigações da área - apresentam potencialidades no que tange à inclusão dos alunos surdos e ouvintes no ensino de Ciências. Estas correspondem as metodologias ativas de ensino e as atividades de cunho investigativo que, segundo os trabalhos analisados por Santana e Sofiato (2018), apresentam como potencialidades: o entusiasmo e a motivação dos alunos; o desenvolvimento da autonomia; o aumento do interesse por conhecimentos das áreas das Ciências; o desenvolvimento de habilidades correspondentes a resolução de problemas e a construção de uma argumentação com fundamentação pelos alunos (Santana \& Sofiato, 2018).

Assim como a PC, a PSR menciona as estratégias utilizadas para a concretização da inclusão escolar da aluna surda nos momentos de AEE. Diante disso, como a segunda língua do surdo é a Língua Portuguesa e esta deve ser ensinada na modalidade escrita no contexto de uma escola bilíngue, a PSR discute que realiza um planejamento voltado para o ensino de Libras articulando-a com a Língua-Portuguesa. De acordo com a PSR, 
o intuito é que a aluna atinja o aprendizado das duas línguas, visto que a maioria dos professores e dos alunos da escola não tem o conhecimento da Libras. Para o ensino das duas línguas, a PSR recorre à apostilas, aplicativos como o Hand Talk, jogos, ensino de classificadores, fonte em Libras, entre outros recursos.

A PSR também elenca as principais dificuldades manifestadas pela aluna na educação, sendo elas: a interpretação de textos e de palavras com sentidos abstratos, bem como a interpretação das informações ditas pelo professor. Neste sentido, a PSR recorre à um planejamento voltado para atividades que exercitem tal habilidade. Como estratégia, a docente se utiliza do apreço da aluna pela disciplina de matemática e propõe atividades que a estimulem ao exercício da intepretação, visto que esta habilidade se faz necessária para o entendimento de todas as disciplinas, inclusive a de Ciências.

A dificuldade diante da intepretação de textos é uma condição recorrente na educação de alunos surdos segundo Goés (2012). A autora demonstrou em seus estudos que a maioria dos alunos surdos analisados apresentou desvios quanto às regras de construção da Língua Portuguesa ${ }^{2}$. De acordo com a autora, tais dificuldades estão diretamente relacionadas às experiências de linguagem vivenciadas pelos estudantes nos anos iniciais da educação.

Goés (2012), nessa perspectiva, evidencia a importância da inserção, logo na Educação Infantil, do ensino de Libras. Contudo, para que esta reformulação na educação ocorra, os professores ouvintes, responsáveis pela alfabetização, devem também ser capacitados para o uso da Libras e da Língua Portuguesa. Além disso, a autora também aponta a necessidade da formação de professores surdos para atuação nesse nível de ensino. Por outro lado, Silva (2015) problematiza como as políticas educacionais brasileiras mantém-se distantes no que tange à preconização de uma formação inicial de professores que os instrumentalizem para promover uma educação inclusiva. A autora discute,

Ora, se os egressos dos cursos de pedagogia são, em regra, os responsáveis pelo processo de alfabetização dos estudantes em geral, como poderá um professor, que não recebeu uma formação ampliada, inclusive bilíngue, se tornar capaz de alfabetizar um estudante surdo? [...] Isto ocorre na visão das políticas educacionais brasileiras, que não atuam preocupadas com esta realidade, transferindo para o professor e demais profissionais da educação a responsabilidade de assumir essa demanda na formação continuada e para o estudante da educação especial, o peso das dificuldades encontradas no processo de escolarização e, em muitos casos, do fracasso ocorrido (Silva, 2015, p. 698).

Cabe ressaltar que as experiências de linguagem vivenciadas pela aluna surda nos anos iniciais da educação regular foram marcadas por obstáculos no tocante

2 A autora menciona que, na educação de surdos, são recorrentes desvios quanto às regras da Língua Portuguesa tais como "o uso inadequado ou omissão de proposições; terminação verbal não correspondente à pessoa do verbo; inconsistência de tempo e modo verbal (sobretudo alternância inadequada de presente e passado e terminação incorreta para tempo e pessoa do verbo)" (Goés, 2012, p. 6). 
à acessibilidade, o que pode ser evidenciado na seguinte fala de $\mathrm{M} 1$ ao se tratar da transferência da filha da escola especial para a escola regular aos cinco anos de idade,

$\mathrm{Na}$ APAE [Associação de Pais e Amigos dos Excepcionais] era bilíngue, trabalhavam tanto o Português quanto a Libras, mas na escola regular não, só o Português e não tinha intérprete. Ela [aluna] fazia leitura labial das professoras. Não foi bilíngue porque ali eles [os professores] não sabiam a Libras, né? Ela tinha dificuldade nas matérias, eu tinha que ajudar ela bastante. (M1)

Quanto à complementação ao ensino de Ciências promovida no AEE e assegurada pela Resolução n. 4 (Resolução n. 4, 2009), os dados demonstraram que esta é realizada apenas por meio de demandas da aluna em momentos de avaliação. Esta circunstância é identificada na seguinte fala de PSR:

Quando ela [aluna] chega com a matéria para estudar, eu pego o caderno dela e a gente vai olhando. Depois, eu passo um vídeo com bastante imagens para ela assimilar o que tá falando ali naquele conteúdo, porque tem muita coisa, tipo nomes técnicos, que são muito difíceis de ela gravar como que escreve, por ela não ouvir. Então ela tem que decorar, [...] para depois na prova ela saber escrever. (PSR)

Nesse trecho, a PSR aponta que os termos científicos são "decorados" pela aluna, não havendo uma compreensão dos termos e dos símbolos como inerentes à linguagem da Ciência, com significados próprios. Essa visão deformada da natureza da Ciência, como um conjunto de nomes e de termos desvencilhados da realidade do aluno, é comumente difundida por professores e por livros didáticos, conforme apontado por Gil Pérez et al. (2001). Segundo os autores, o trabalho científico ainda é visto na escola de forma rígida, parcelada, analítica e com conceitos descontextualizados das vivências de cada aluno. Diante disso, Gil Pérez et al. (2001) apresentam uma série de alternativas a serem trabalhadas no ensino de Ciências para que tais visões deformadas sejam desmistificadas. Um exemplo é a inclusão de temas que abordem as relações entre Ciência, Tecnologia e Sociedade. Estes temas poderiam contribuir para a contextualização dos conteúdos de Ciências e para demonstrar a sua importância, impacto e aplicação em diferentes âmbitos da sociedade e do meio ambiente, não visualizando-os como um conjunto de termos e de processos a serem memorizados para os exames avaliativos (Gil Pérez, et al., 2001).

Os materiais confeccionados pelos alunos na disciplina de Ciências são deixados à disposição para os demais setores presentes na escola. Assim, a PSR também afirma a estratégia de ensinar Ciências por meio da exploração de recursos visuais e de materiais concretos. Entretanto, os professores das áreas não-pertencentes às Ciências Naturais, que se utilizam desses materiais devem estar inteirados de que estes modelos podem não condizer com a realidade. Essa assimilação inadequada é o que Bachelard (1996) chama de obstáculos epistemológicos, em que o conhecimento comum se torna um empecilho para a construção do conhecimento científico. Para Bachelard (1996), o obstáculo 
realista ocorre quando a investigação científica é proposta dentro de um material concreto, porém ela não evolui para o abstrato. Um exemplo desta situação encontra-se na representação de átomos como esferas maciças, sem abstrair para a existência de um grande espaço vazio existente entre o núcleo e a eletrosfera (Figura 4).

Figura 4. Material didático sobre modelos atômicos utilizados no AEE

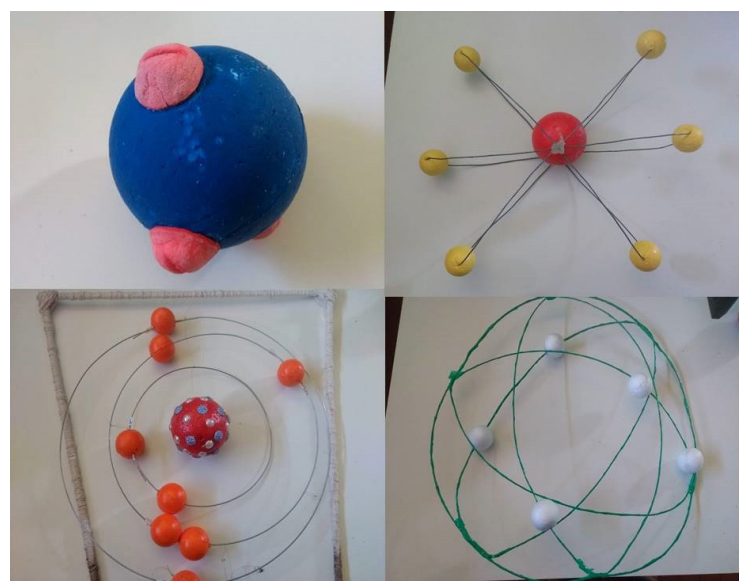

Fonte: Dados de pesquisa.

Assim como a PC e a PSR, o IEA também aponta algumas estratégias utilizadas durante a interpretação de termos científicos em sala de aula.

Em razão da recente oficialização da Libras (Lei n. 10436, 2002) e das políticas públicas voltadas para a inclusão escolar no país (MEC, 2008), muito ainda se tem a avançar no que tange à evolução da Libras referente a termos das Ciências Naturais, que ainda carecem de sinais correlatos. Portanto, diante do desconhecimento de sinais em sala de aula, o IEA manifesta que recorre à utilização da datilologia, ou soletração digital, para a interpretação de termos científicos. Todavia, a datilologia demanda tempo e considerando um contexto de uma sala de aula, o tempo para interpretação é escasso, haja vista que o professor dá continuidade à explicação do conteúdo. Diante disso, o IEA esclarece que realiza a estratégia de criar, em conjunto com a aluna surda, um sinal não-oficial para aquele termo, o qual, em sua maioria corresponde a uma abreviação da própria palavra.

Outra estratégia mencionada pelo IEA durante o ensino de Ciências corresponde a exploração do quadro negro para evidenciar à aluna surda as palavras, os tópicos e as imagens que são apresentadas pela professora. Além disso, o IEA realiza a exploração de imagens em smartphone e em livro didático. Esta atividade é exemplificada em sua fala: "[...] às vezes eu procuro... se o professor fala alguma coisa lá, ah tem uma célula... mas ele não trouxe uma imagem, eu procuro no celular e mostro" (IEA).

Segundo Oliveira e Benite (2015b), quando os intérpretes recorrem a recursos didáticos para complementar as suas interpretações e para ensinar Ciências ao aluno surdo, estes confundem seu papel em sala de aula com o papel de outros profissionais, visto que a função de adequar às aulas e fornecer recursos para a facilitação da aprendizagem 
é primeiramente do professor de Ciências. Vale ressaltar também, que o intérprete não dispõe de uma formação na área das Ciências para selecionar materiais adequados, ou seja, modelos científicos que não contenham falhas conceituais. O mesmo pode ser dito no que diz respeito à seleção de materiais didáticos pelo professor do AEE, conforme discutido anteriormente.

Após a explanação das estratégias utilizadas pelos profissionais como forma de fornecer "rotas alternativas" aos alunos surdos, visando neutralizar as barreiras presentes no espaço escolar, apresenta-se, no subitem a seguir, a exploração das dificuldades vivenciadas por cada um deles com o intuito de promover uma maior compreensão acerca dos cenários de educação regular brasileira, fornecendo subsídios para se pensar em formas de superação desses obstáculos.

\section{Desafios e dificuldades encontrados pelos profissionais diante do ensino de Ciências e da surdez}

O despreparo para receber um aluno surdo em sala de aula é a principal dificuldade apontada pela PC e pela PSR, que também salientam como o desconhecimento em Libras acarreta a impossibilidade de comunicação com a aluna.

Cabe destacar que, com o propósito de possibilitar a inclusão dos alunos surdos e promover a comunicação entre professor e aluno, o Decreto n. 5626, de 22 de dezembro de 2005 , em seu artigo $3^{\circ}$, assegura que a Libras deve ser inserida como disciplina curricular obrigatória nos cursos de formação de professores e como disciplina curricular optativa nos demais cursos de educação superior (Decreto n. 5626, 2005). Entretanto, a carga horária nos cursos de formação destinada à disciplina de Libras é reduzida, o que impossibilita adquirir a fluência nessa modalidade, evidenciando, portanto, a necessidade de formações complementares, conforme explicitado anteriormente por Silva (2015).

Diante da defasagem dos professores nesse sentido, ainda não há consenso sobre o lugar adequado para a educação dos surdos. Ramos e Hayashi (2018) apontam que, apesar de as políticas públicas, como a Política Nacional de Educação Especial na Perspectiva Inclusiva (PNEE-EI) (MEC, 2008) assegurarem a educação dos surdos preferencialmente na rede regular de ensino, parte da comunidade surda contesta tais documentos legais, reivindicando o direito da educação com seus pares mediante escolas e classes específicas para surdos, visando a valorização das especificidades linguísticas e culturais da comunidade surda. Isso porque as vivências de muitos alunos surdos em escolas inclusivas regulares ainda são excludentes, visto que a maioria das pessoas é ouvinte e a língua privilegiada é a Língua Portuguesa. Assim, a Libras está presente apenas via intérprete, AEE e momentos pré-definidos, impossibilitando a aquisição natural da Língua de Sinais e contribuindo para uma comunicação fragmentada e restrita do surdo (Ramos \& Hayashi, 2018).

A PSR também enfatiza a dificuldade diante da transformação da teoria em um recurso concreto ou uma atividade prática ao afirmar: 
Para você criar esse objeto para ela compreender o que está sendo tratado naquele assunto é um pouco complicado, o meu maior desafio é isso, ficar correndo atrás, pesquisando para estar transformando a teoria numa parte concreta para ela estar compreendendo. (PSR)

Segundo Rossetto (2015), muito ainda se tem a discutir acerca da formação do professor do AEE para o exercício na SRM. Segundo a autora, o AEE não tem previsão para uma formação inicial e sua formação consiste, basicamente, em cursos de formação continuada e especialização. A via principal para a formação continuada de professores nesse contexto é a modalidade de Educação a Distância (EAD).

Uma crítica à essa formação é apresentada pela autora,

[...] embora os cursos de EAD, on-line, abarquem a formação de grande quantidade de profissionais e pareçam uma estratégia convidativa e confortável, escondem uma formação docente limitada e aligeirada que, supostamente, é justificada pela urgência de formar o profissional para uma tarefa imediata. Dessa forma, o professor enfrenta o dilema de conduzir o processo de ensino/aprendizagem rumo à humanização dos alunos, quando sua própria formação é comprometida. O professor do AEE tem atribuições diversas em campos de conhecimento específicos, mas, para o desempenho de sua função, contraditoriamente, colocase uma formação cuja consistência é questionável (Rossetto, 2015, p. 109).

Dessa forma, é notório que existem dificuldades no que diz respeito ao conhecimento específico das Ciências Naturais, bem como das demais disciplinas presentes no contexto escolar. Isso evidencia a relevância de uma formação consistente que lhe dê subsídios teóricos, além da ênfase nos procedimentos técnicos (Rossetto, 2015).

Discutindo acerca das dificuldades vivenciadas pelo IEA na interpretação de aulas de Ciências, este destaca como principal desafio a não-fluência em Libras pela aluna surda, o que o leva a assumir para si a função de instrutor de Libras. Estes achados vão ao encontro dos trabalhos de Brito, Freire, Barbosa e Fernandes (2019) e Oliveira e Benite (2015b), os quais mencionam os desafios acerca da inclusão tardia do aluno surdo nas escolas regulares e a sobrecarga de funções direcionada ao intérprete em razão disso.

Cabe destacar que a Libras também é ensinada à aluna surda durante os momentos de AEE pela PSR. Entretanto, como a PSR não é fluente na língua, o intérprete a auxilia neste processo - aspecto que será discutido posteriormente.

Além disso, o IEA também aponta como dificuldade o seu desconhecimento em relação aos conceitos e as nomenclaturas presentes no campo das Ciências Naturais, visto que, em sua formação, esses conceitos não foram abordados. De acordo com Lacerda (2014), pouco se sabe acerca da formação do intérprete para atuar no cenário educacional. Segundo a autora, a interpretação educacional se trata de uma atividade emergente, que se constrói e se constitui pela prática cotidiana do fazer. Assim, diante 
da lacuna no que diz respeito à sua formação, o IEA declara a necessidade de estudos e aprimoramentos constantes para o exercício da interpretação em aulas de Ciências.

Discutidas as principais dificuldades vivenciadas pelos atores escolares, parte-se para a discussão acerca dos pontos de articulação entre os profissionais no subitem a seguir.

\section{Os pontos de articulação entre a professora de Ciências, o AEE e o IE}

Ao que concerne à articulação entre os profissionais investigados nesta pesquisa, foi possível evidenciar, por meio das entrevistas, que a profissional responsável pelo planejamento das aulas é a PC. Esta mantém uma articulação com PSR, principalmente pela última desempenhar também a função de supervisora escolar. As professoras esclarecem:

Ela [professora de AEE] tem o acesso ao planejamento, a gente passa para ela antes, porque ela é a supervisora. Eu pergunto para ela, pra ela ver se tá de acordo. (PC)

Eu sou supervisora da escola, então tem totalmente uma ligação, porque eu tenho que ver o planejamento do professor. Assim tenho como auxiliar esse professor, esse professor também me pergunta, sempre quando precisa fazer uma atividade concreta, um trabalho, ela vem me perguntar 'o que você acha de fazer isso, aquilo?'. (PSR)

Às vezes eu passo a prova para professora do AEE, aí ela vem aqui dá uma olhadinha na prova antes, eu sempre converso muito isso com ela, se eu dou a mesma prova, se eu faço uma prova adaptada...(PC)

A Figura 5 apresenta uma transcrição da seção do Plano de Desenvolvimento Individual (PDI), elaborado pela PSR em conjunto com a PC sobre as possibilidades e as dificuldades referentes à aprendizagem da aluna na disciplina de Ciências.

Figura 5. PDI em articulação com a disciplina de Ciências

\begin{tabular}{|l|l|l|}
\hline $\begin{array}{l}\text { Habilidades acadêmicas } \\
\text { observadas }\end{array}$ & Conhecimentos e capacidades & $\begin{array}{l}\text { Dificuldades que o aluno } \\
\text { apresenta }\end{array}$ \\
\hline Ciências & $\begin{array}{l}\text { Força de vontade, atenciosa, interessada e e } \\
\text { responsável. }\end{array}$ & Interpretação. \\
\hline
\end{tabular}

Plano de Intervenção Pedagógica (para sanar as dificuldades apresentadas pelo aluno):

\begin{tabular}{|l|l|l|}
\hline Área & Planejamento pedagógico & Intervenção pedagógica \\
\hline Ciências & Uso de material concreto, uso de imagens. & $\begin{array}{l}\text { Experimento mostrando o } \\
\text { conteúdo estudado; } \\
\text { Fotos, banners e vídeos. }\end{array}$ \\
\hline
\end{tabular}

Fonte: Dados de pesquisa. 
Segundo Mendes e Malheiro (2012), o trabalho colaborativo entre o professor da classe regular e o professor do AEE é uma estratégia em ascensão, visto que pode contribuir, tanto para o ensino aos alunos, quanto para o desenvolvimento dos educadores. Nesse trabalho, os profissionais podem unir as suas áreas de conhecimento para enfrentar as dificuldades perante o ensino à um público diversificado.

Esta junção de diferentes perspectivas e conhecimentos também ocorre no âmbito da articulação entre a PSR e o IEA. Segundo os participantes:

Às vezes o aluno tá fazendo um sinal pra ela [professora do AEE] e ela não entende, aí ela me chama, aí eu explico tanto para o surdo quanto para o professor de AEE. (IEA)

Ele [intérprete] trabalha na sala com ela, só que de vez em quando ele vai com ela também na minha sala para ajudar, porque de vez em quando eu tô com dúvida, eu não tô conseguindo. Igual os nomes científicos, tem coisa que eu não sei. (PSR)

A importância do trabalho colaborativo nesse âmbito destaca-se, principalmente, em função dos desafios que o serviço do AEE carrega. Isto porque as políticas públicas mencionam que este professor deve possuir conhecimentos acerca de toda diversidade que compõe o PAEE, bem como deve promover a complementação ou a suplementação de todos conteúdos disciplinares lecionados na sala regular. Esse processo se tensiona tendo em vista as incongruências referentes à formação desse professor, conforme explicitado anteriormente por Rossetto (2015).

Uma das atribuições do professor do AEE corresponde ao ensino da Libras e da Língua Portuguesa ao aluno surdo, mesmo não possuindo a fluência em Libras, o que evidencia a importância do suporte fornecido pelo IEA nesse processo.

Por fim, que diz respeito à articulação entre o IEA e a PC, os participantes mencionam,

O intérprete encontra com o professor mais na hora de intervalo, mais na hora de almoço ou no módulo coletivo que eles conversam mais. Que é uma vez por semana. (IEA)

Ele [intérprete] não tem acesso ao planejamento antes de eu dar aula, o professor de apoio sim. (PC)

Nas falas expostas, é evidente que, ao contrário do que acontece no âmbito da PSR e a PC, bem como entre a PSR e o IEA, o mesmo não ocorre em relação a articulação entre o IEA e a PC, haja vista que o IEA não tem acesso ao planejamento, bem como não participa de sua elaboração. Além disso, não são disponibilizados horários para o diálogo entre os profissionais, em decorrência da alta demanda de atividades que desempenham. Os participantes afirmam existir uma colaboração apenas durante as aulas de Ciências, quando a PC se atenta ao tempo disponível para a interpretação, realizando pausas e 
perguntando ao intérprete se o mesmo tem conseguido acompanhar as suas explicações.

Segundo Lacerda et al. (2018), essa parceria pode contribuir pelo fato de o intérprete de Língua de Sinais apresentar um maior contato com a comunidade surda e com os aspectos da surdez, o que poderia trazer contribuições valiosas para as práticas educacionais do professor regente.

Além disso, por meio do contato com o planejamento da disciplina, o intérprete poderá pesquisar acerca dos sinais que serão utilizados, discutir suas dúvidas e procurar meios para se aprofundar na temática juntamente com o professor, de modo a não prejudicar a sua interpretação durante a aula. Nesta perspectiva, o professor regente assume a posição de auxiliador de uma formação que, na maioria das vezes, se dá por meio da prática cotidiana (Lacerda et al., 2018).

É nesse sentido que Lacerda e Polleti (2009, p. 175) apontam que,

(...) a presença do intérprete em sala de aula e o uso da língua de sinais não garantem que as condições específicas da surdez sejam contempladas e respeitadas nas atividades pedagógicas. Se a escola não atentar para a metodologia utilizada e currículo proposto, as práticas acadêmicas podem ser bastante inacessíveis ao aluno surdo, apesar da presença do intérprete.

Contribuindo com a discussão acerca da reestruturação do ambiente escolar, Dorziat (2009) salienta que a aceitação da Língua de Sinais nos espaços educacionais representou um avanço considerável quanto aos objetivos das pessoas surdas em possuírem melhores condições de participação social. Entretanto, a autora afirma que a utilização da Língua de Sinais toma corpo apenas como aparato legal e valor simbólico quando os sistemas organizacionais continuam vigorando com a utilização de políticas homogêneas e unilaterais. Para a autora, “(...) se acata a diferença, mas mantém-se o mesmo tipo de submissão dos indivíduos às estruturas existentes” (Dorziat, 2009, p. 23).

De modo a finalizar as discussões, no item a seguir, são apresentadas as conclusões e implicações da presente pesquisa.

\section{Conclusões e Implicações}

Este estudo objetivou contribuir com as discussões no que tange à inclusão escolar dos alunos surdos nas escolas regulares, evidenciando como as políticas públicas se legitimam na prática cotidiana de uma escola da rede pública situada ao sul de Minas Gerais. Para isso, foi investigado o caso da inclusão escolar de uma aluna surda, focalizando os serviços proporcionados para a sua inclusão no ensino de Ciências.

A caracterização das estratégias utilizadas pelos profissionais no ensino/ interpretação da disciplina de Ciências evidenciou a busca dos profissionais pela promoção de "rotas alternativas" para o ensino e aprendizagem - tendo em vista as especificidades linguísticas da aluna surda - sendo algumas delas: i) A utilização de recursos visuais e materiais concretos para o ensino (adotada pela professora de Ciências); ii) O estímulo do exercício da interpretação de textos utilizando como facilitadores os 
problemas matemáticos (realizado pela professora do AEE); e iii) A criação de sinais não-oficiais para os termos científicos, juntamente com a exploração de imagens (ações realizadas pelo intérprete educacional).

Entretanto, o cenário investigado de inclusão da aluna surda no ensino de Ciências evidenciou a multiplicidade de variáveis que perpassam este contexto, sendo a formação insuficiente dos profissionais, a principal causa de suas dificuldades. No caso da professora de Ciências, esta desconhece a Língua de Sinais, o que impede a sua comunicação com a aluna surda; No caso do intérprete educacional, este desconhece os conceitos científicos e os sinais correspondentes à linguagem científica; Já no caso da professora do AEE, esta apresenta dificuldades tanto no que se refere ao conhecimento da Língua de Sinais, quanto no que concerne aos conhecimentos científicos.

Entende-se que estes achados, não destoantes da literatura da área (Brito et al., 2019; Lacerda \& Poletti, 2009; Oliveira \& Benite 2015a; Oliveira \& Benite, 2015b; Oliveira et al., 2012) podem subsidiar a estruturação de políticas públicas educacionais voltadas para a formação dos professores e dos intérpretes, de modo que esta formação os instrumentalizem para proporcionar um ensino/interpretação de qualidade nos ambientes educacionais.

Como uma possibilidade de neutralizar as barreiras presentes no ensino de Ciências aos alunos surdos, bem como fomentar as lacunas no que tange às pesquisas sobre as interações entre os diferentes profissionais escolares, atentou-se também neste estudo, às possibilidades de articulação entre os diferentes âmbitos escolares, em uma perspectiva colaborativa entre o professor regente, o AEE e o intérprete educacional. Neste sentido, evidenciou-se que esta articulação tem ocorrido de forma constante entre AEE e a classe regular, bem como entre o AEE e o intérprete educacional, minimizando, desta forma, os desafios advindos da inclusão escolar. Entretanto, esta perspectiva mantém-se limitante quanto ao diálogo entre a classe regular e o intérprete educacional, dificultando, por consequência, o trabalho do intérprete.

Diante disso, este trabalho, dando voz aos professores e intérpretes, pôde evidenciar, ainda que em um cenário restrito, a necessidade de reorganização das escolas em prol do trabalho colaborativo, de modo a não prejudicar a atuação dos profissionais e o desempenho dos alunos surdos.

A partir das discussões e reflexões promovidas neste trabalho, algumas sugestões no que tange à organização escolar com o intuito de beneficiar o ensino de Ciências aos alunos surdos podem ser elencadas, como: i) Planejar aulas utilizando recursos visuais e materiais concretos, assim como fazer uso de atividades experimentais e investigativas; ii) Enviar, com antecedência, o planejamento da disciplina aos intérpretes educacionais, auxiliando-os diante de suas dúvidas referentes aos conteúdos científicos; iii) Promover um ambiente de trabalho colaborativo entre os diferentes âmbitos escolares por meio de momentos de diálogo, de modo com que cada profissional contribua a partir de sua área de conhecimento; iv) Incentivar a aprendizagem da Libras à toda comunidade escolar para que todos consigam comunicar-se com os alunos surdos presentes na escola; v) 
Estabelecer um diálogo com universidades e comunidades surdas, de modo a ampliar e disponibilizar os sinais em Libras correspondentes à termos científicos.

Cabe destacar, por fim, que esta investigação apresentou limitações, haja vista que não foi possível acompanhar de perto o dia-a-dia de trabalho dos profissionais, bem como o cotidiano da aluna surda em suas interações com a disciplina de Ciências. Diante disso, esta pesquisa abre caminhos para pesquisas colaborativas e de investigaçãoação em contextos escolares, de modo a se aprofundar nas potencialidades do trabalho colaborativo como forma de suprir as dificuldades advindas das insuficiências formativas dos profissionais. Além disso, a visão da gestão escolar sobre a inclusão dos alunos surdos nas escolas regulares poderia promover uma discussão mais ampliada do contexto escolar analisado.

Este trabalho não objetivou esgotar a discussão acerca da temática sobre o ensino de Ciências aos alunos surdos, mas analisar o cenário de inclusão escolar de uma aluna surda no ensino de Ciências de modo a subsidiar reflexões e ações que possam tornar a educação inclusiva, visando romper com as barreiras atitudinais, organizacionais e formativas ainda existentes nesse processo.

\section{Referências}

Bachelard, G. (1996). A formação do espírito científico: Contribuição para uma psicanálise do conhecimento. Contraponto.

Bardin, L. (2011). Análise de Conteúdo. São Paulo: Edições 70.

Brito, M. D., Freire, K. M., Barbosa, A. J., \& Fernandes, M. A. (2019). O instrutor/ intérprete de Libras no contexto educacional: Desafios linguísticos no processo tradutório. Psicologia \& Saberes, 8(11), 109-126. https://doi.org/10.3333/ps.v8i11.975

Crittelli Amado, B. (2017). Aprendendo a ouvir aqueles que não ouvem: O desafio do professor de ciências no trabalho com a linguagem científica com alunos Surdos. (Dissertação de Mestrado em Ensino de Ciências). Programa de Pós-Graduação Interunidades em Ensino de Ciências da Universidade de São Paulo, São Paulo.

Decreto n. 5.626, de 22 de dezembro de 2005 (2005). Dispõe sobre a Língua Brasileira de Sinais-Libras. http://www.planalto.gov.br/ccivil_03/_ato2004-2006/2005/decreto/ d5626.htm

Dorziat, A. (2009). O outro da educação: Pensando a surdez com base nos temas Identidade/Diferença, Currículo e Inclusão. Vozes.

Galvão Filho, T. A. (2012). Tecnologia assistiva: Favorecendo o desenvolvimento e a aprendizagem em contextos educacionais inclusivos. In C. R. Giroto, R. B. Poker, \& S. Omote (Orgs.), As tecnologias nas práticas pedagógicas inclusivas (pp. 65-92). Oficina Universitária. marilia.unesp.br/Home/Publicacoes/as-tecnologias-nas-praticas_ebook.pdf 
Gil Pérez, D., Montoro, I. F., Alís, J. C., \& Praia, J. (2001). Para uma imagem não deformada no trabalho científico. Ciência \& Educação, 7(2), 125-153. https://doi.org/10.1590/ S1516-73132001000200001

Goés, M. C. (2012). Linguagem, surdez e educação (4ª ed.). Autores Associados.

Lacerda, C. B. (2014). Intérprete de Libras em atuação na educação infantil e no ensino fundamental. Porto Alegre: Mediação/FAPESP.

Lacerda, C. B., \& Poletti, J. E. (2009). A escola inclusiva para surdos: A situação singular do intérprete de língua de sinais. In O. Fávero, W. Ferreira, T. Ireland, \& D. Barreiros, Tornar a educação inclusiva (pp. 159-177). UNESCO.

Lacerda, C. B., Santos, F. L., \& Caetano, J. F. (2018). Estratégias metodológicas para o ensino de alunos surdos. In C. B. Lacerda, \& L. F. Santos, Tenho um aluno surdo, e agora? Introdução à Libras e a educação dos surdos (pp. 185-200). EdUFSCar.

Lei n. 9.394, de 20 de dezembro de 1996 (1996). Estabelece as diretrizes e bases da educação nacional. Diário Oficial [da] República Federativa do Brasil, Brasília. http:// www.planalto.gov.br/ccivil_03/leis/19394.htm

Lei n. 10.436, de 24 de abril de 2002 (2002). Dispõe sobre a Língua Brasileira de Sinais Libras e dá outras providências. Brasília. http://www.planalto.gov.br/ccivil_03/leis/2002/ 110436.htm

Lorenzini, N. M. P. (2004). A aquisição de um conceito científico por alunos surdos de classes regulares do ensino fundamental. (Dissertação de mestrado em Educação). Programa de Pós-Graduação em Educação Científica Tecnológica da Universidade Federal de Santa Catarina, Florianópolis.

MEC (Ministério da Educação) (1994). Declaração de Salamanca. Sobre Princípios, Políticas e Práticas na Área das Necessidades Educativas Especiais. Unesco. http://portal. mec.gov.br/seesp/arquivos/pdf/salamanca.pdf

MEC (Ministério da Educação) (2008). Política de Educação Especial na perspectiva da Educação Inclusiva. Secretaria de Educação Especial. http://portal.mec.gov.br/arquivos/ pdf/politicaeducespecial.pdf

Mendes, E. G., \& Malheiro, C. A. (2012). Salas de recursos multifuncionais: É possível um serviço "tamanho único" de atendimento educacional especializado? In T. G. Miranda, \& T. A. Galvão Filho, O professor e a educação inclusiva: formação, práticas e lugares (pp. 349-366). Salvador, BA/Brasil: EDUFBA. https://repositorio.ufba.br/ri/bitstream/ ri/12005/1/o-professor-e-a-educacao-inclusiva.pdf

Oliveira, J. F., Ferraz, D. A., \& Ribeiro, V. M. (2019). Possibilidades de Articulação entre o Atendimento Educacional Especializado e o Ensino de Ciências: Um estudo sobre inclusão. Revista Ciências \& Ideias, 10(2), 56-72. http://dx.doi.org/10.22407/2019. v10i2.950 
Oliveira, W. D., \& Benite, A. M. (2015a). Aulas de ciências para surdos: estudos sobre a produção do discurso de intérpretes de LIBRAS e professores de ciências. Ciênc. Educ., Bauru, 21(2), 457-472. http://dx.doi.org/10.1590/1516-731320150020012

Oliveira, W. D., \& Benite, A. M. (2015b). Estudos sobre a relação entre o intérprete de LIBRAS e o professor: Implicações para o ensino de ciências. Revista Brasileira de Pesquisa em Educação em Ciências, 14(3), 597-626. Recuperado de https://periodicos. ufmg.br/index.php/rbpec/article/view/4331

Oliveira, W. D., Melo, A. C., \& Benite, A. M. (2012). Ensino de ciências para deficientes auditivos: Um estudo sobre a produção de narrativas em classes regulares inclusivas. Revista Electrónica de Investigación en Educación en Ciencias, 7(1), 1-10.

Quadros, R. M. (2004). O tradutor e intérprete de língua brasileira de sinais e língua portuguesa. http://portal.mec.gov.br/seesp/arquivos/pdf/tradutorlibras.pdf

Ramos, D. M., \& Hayashi, M. C. (2018). O Lugar da Educação de Surdos nas Dissertações e Teses. Revista Brasileira de Educação Especial, 24(3), 247-260. https://doi.org/10.1590/ s1413-65382418000200007

Resolução n. 2, de 11 de setembro de 2001 (2001). Institui as Diretrizes Nacionais para a Educação Especial na Educação Básica. Brasília. http://portal.mec.gov.br/arquivos/pdf/ resolucao2.pdf

Resolução n. 4, de 02 de outubro de 2009 (2009). Institui Diretrizes Operacionais para o Atendimento Educacional Especializado na Educação Básica, modalidade Educação Especial. Brasília. http://portal.mec.gov.br/dmdocuments/rceb004_09.pdf

Rossetto, E. (2015). Formação do professor do atendimento educacional especializado: A Educação Especial em questão. Revista Educação Especial, 28(51), 103-116. https:// doi.org/10.5902/1984686X13367

Santana, R. S., \& Sofiato, C. G. (2018). O estado da arte das pesquisas sobre o ensino de Ciências para estudantes surdos. Práxis Educativa, 13(2), 596-616. https://doi. org/10.5212/PraxEduc.v.13i2.0019

Santos, A. N., \& Lopes, E. T. (2017). Ensino de Ciências para surdos e/ou deficientes auditivos numa perspectiva de inclusão escolar: Um olhar sobre as publicações brasileiras no período entre 2000 e 2015. Debates em Educação, 9(17), 183-203. https:// doi.org/10.28998/2175-6600.2017v9n18p183

Silva, L. C. (2015). Formação de professores: desafios à educação inclusiva. Revista IberoAmericana de Estudos em Educação, 10(especial), 691-701. https://doi.org/10.21723/ riaee.v10i5.7920

Vigotsky, L. V. (1997). Obras escogidas V: fundamentos de defectologia. Visor.

Yin, R. K. (2001). Estudo de caso: planejamento e métodos (2a ed.). Bookman.

Yin, R. K. (2016). Pesquisa qualitativa do início ao fim. Penso. 


\author{
Juliani Flávia de Oliveira \\ Universidade Federal de Itajubá \\ Itajubá, Minas Gerais, Brasil \\ juliani.oliveira@unifei.edu.br \\ Denise Pereira de Alcantara Ferraz \\ Universidade Federal de Itajubá \\ Itajubá, Minas Gerais, Brasil \\ deferraz@unifei.edu.br
}

Editor Responsável

Stefannie Ibraim

Manifestação de Atenção às Boas Práticas Científicas e de Isenção de Interesse

As autoras declaram ter cuidado de aspectos éticos ao longo do desenvolvimento da pesquisa e não ter qualquer interesse concorrente ou relações pessoais que possam ter influenciado o trabalho relatado no texto. 